\title{
Small Scale Industries and Rural Development in Edo State, Nigeria
}

\author{
Oboniye Juliana A \\ Department of Economics, \\ College of Education Igueben, Edo State, Nigeria
}

\section{Doi:10.5901/jesr.2013.v3n9p25}

\begin{abstract}
The future of the industrial development of this nation depends to a large extent on the growth and development of the potentials of small and medium scale enterprises (SMEs). Small scale industries play a considerable role in the employment of manpower and productivity, distribution of income across the regions through increased investments and profits. In fact, they are termed 'rural developing motors'. The objective of this study is to highlight the roles and constraints of small scale industries in the rural development of Edo state. The data collected were obtained through field observations, oral interviews and questionnaire administration. The data received were analysed using statistical techniques. Findings revealed that small scale industries have seriously impacted in the area of employment and household income generation .It also shows that there is lack of management skills, poor record keeping and weak access to financing.
\end{abstract}

Keywords: Rural development, small scale industries, employment, growth and development.

\section{Introduction}

"About $70 \%$ of Africa's poor are rural and Nigeria's population is predominantly rural with rural community dwellers making up 70\% of the total population" (Onyenechere, 2010).

Rural development generally refers to the process of improving the quality of life and economic well being of people living in relatively isolated and sparsely populated area. The need for rural communities to approach development from a wider perspective has created more focus on a broad range of development goals rather than merely creating incentives for agricultural or resource based businesses. Education, entrepreneurship, physical infrastructure and social infrastructure all play an important role in developing rural regions.

In recent years, many third world countries have come to realize that the development strategies they pursued in the past three decades were inappropriate and in some cases irrelevant to their real needs. They have also come to realize that a development strategy aimed primarily at economic growth and Gross domestic Product (GDP) will not by itself solve problems of employment, income distribution or improve the condition of the poorest segments of the population.

Adejumo and Olaoye (2012) observed that:

After early 1960s, the Nigerian government pursued the programme of import substitution industries (ISI) more vigorously than "the processing of raw materials for exports" programme which she did before 1954. The programme of ISI and export processing did not generate employment opportunity proportionately to the number of accumulating manpower, other problems include: regional economic disparities undue concentration of wealth and powers in the hands of few people in the urban centre, wasteful utilization of productive resources and mass migration of youths from rural areas to urban centers. 
The migration of youths from rural areas to urban areas is a resultant effect of increased rural population, unemployment of rural people, decreased inputs of rural people's income and high supply of labour in rural areas. In order to address the various problems mentioned above, the Federal and State governments decided to try an alternative industrialization strategy development of small scale businesses especially in the early 1970 s.

Most Nigerian small businesses were at one time collage industries that developed into small industries. Most of these are in the rural areas working raw materials such as leather or wool into textiles. According to a 1992 study, the main types of small industries were centered on weaving, baking, welding, shoe making, tailoring or pottery. Most of these were one person operations.

The government has defined "small industry" numerous times over the years depending on the nature of the "development plan".

In general, the government defines a "small industry" as one that employs fewer than 50 people. Older plans define it as employing fewer than 10 people. In addition, the state defines a small business as one that has a basic capital value of less than N500, 000 (\$3,320 US. as of September 2010).

Bachama Nigel Yusuf (2010) observed that:

In all economies, (especially developing economies) small scale industries play important roles in the provision of immediate employment, complementing large and medium scale enterprises in the provision of goods and services, help build supplies of managerial and entrepreneurial skills, promote indigenous technology, ensuring the nation becomes self reliant in agricultural production, help in alleviating poverty especially among the rural communities ensuring equitable distribution of national income and mobilization of resources.

Inspite of the relevance of small scale industries to both developed and developing economies, in Nigeria, the sector faces a lot of problems. These problems include among others; managerial problem, lack of appropriate technology, a harsh policy environment, inadequate infrastructural facilities and finance. This is why inspite of her vast natural and human resources, today, Nigeria is still struggling to survive.

Given the scenario above, the objective is to highlight the roles and constraints of small scale industries in the rural development of Edo State. For SMES to be sustained in this challenging environment there is a need for systematic analysis of their problems and identification of strategies for survival. Some of these SMES are thriving in Nigeria despite the challenging environment as a result of the effective option strategies they have internalized while others have closed shop. It has become important to identify the major problems and the strategies employed by the thriving ones.

\section{The Concept, Functions and Characteristics of Small and Medium Scale Enterprises}

The concept of a small and medium scale enterprise (SME) is quite relative and depends on both the geographical location as well as the nature of the economic activity being performed. This is why literary works as well as legislations and practices of countries lack unanimity on the definition of SMES.

In Nigeria, for instance, among the various definitions used by different agencies include the following:

1. The Central Bank of Nigeria (CBN) defines a small scale enterprise as an enterprise whose total cost, excluding cost of land but including working capital, is above N1.0million but does not exceed N10.0 million (CBN, 1996:7).

2. The Nigerian Directorate of Employment (NDE) defines Small and Medium Scale business in the 1989 National Budget to include project with a capital investment as low as N3,000 and employing as few persons as three persons. 
3. The centre for Industrial Research and Development at the Obafemi University, Ile-Ife defines SMEs as those whose total assets in capital equipment, plant and working capital do not exceed N250,000.00 and employing not more than 50 full time workers.

4. The Nigerian Industrial Development Bank (NIDB) defines Small Scale Enterprises as enterprises with project cost (investment and working capital) not more than N750,000.00 while medium scale enterprises is defined as those business with project cost between the range of N750,000.00 and N3.0 million).

5. The World Bank defines SMEs as those with fixed assets (excluding land) but including cost of the investment project not exceeding N10 million in constant 1988 prices (Umar 1997)

6. The National Economic Reconstruction Fund (NERFUND) defines SMEs as enterprises with fixed assets other than land but inclusive of the cost of new investment not exceeding N10million.

\section{Functions}

1. SMEs constitute the very basis of the Nigerian economy. They have come to realize the value of small businesses. They are seen to be characterized by dynamism, witty innovations, efficiency, and their small size allow for faster decision making process. Governments all over the world have realized their importance and thus have formulated comprehensive public policies to encourage, support and fund them.

2. Ability to generate employment opportunities particularly in the rural areas. Lewis (1974) highlighted one of the contribution of Small Scale Industries as the provision of immediate large scale employment to the unemployed as well as to nearly all marginal labour; such as house wives, students on vacation under aged children, disabled and even a times old age people both skilled and unskilled.

3. Small Scale industries ensure a more equitable distribution of national income and at the same time facilitate effective mobilization of resources (which were hitherto lying idle) of capital and skill.

4. Mobilization and utilization of domestic savings. Initial capital investment for small scale businesses are obtained from the non formal lending sources, that is, from friends, relatives, local money lenders, traditional cooperatives for savings and credit as well as from personal funds. This goes to show that idle funds especially in the rural areas will find their way into productive uses. Associated with this fact is that human beings clever brains and skillful hands are adequately utilized in the process.

5. High local value added since most of their operations are based on the exploitation of indigenous technology. Small scale industries mostly use domestically produced materials inputs including tools, equipment and power which makes it possible for a country to redirect its foreign exchange to other channels of development, especially in the present global economic crisis that seriously impacted on revenue base of the country. The products of these companies could also be exported to earn the country foreign exchange.

6. SMEs help to mitigate rural-urban migration. It can among other things help promote an agro-based industry which is another threshold for development in the rural areas that are industrially backward and thus help curb rural/urban migration in which cities are prone to, thus reducing unemployment, crime and other vices as a result of the menace of such movement. Most importantly is that it complements large industries in producing goods and services which are hitherto imported.

7. It helps to stimulate indigenous entrepreneurship. The development of Small Scale industries seems to carry the greatest hope of truly indigenizing the Nigerian economy. It is the believe of this study that small scale industries can tackle more efficiently certain problems of industrialization. For example, cottage industries as analyzed by some writers, 
as the kind of industries which depends on traditional skills and so can help build supplies, managerial and entrepreneurial skills especially as they are widely distributed over wider regions including rural areas.

\section{Characteristics of Small and Medium Scale Enterprise}

Iregbeyen (1999) opined that:

Our knowledge about SMES will not be enough if we do not know their characteristics which to a large extent, enable them to perform the above function on the one hand and on the other hand pose as a stumbling block, particularly in their ability to source for funds. The main characteristics of SMEs as contained in the literature (Brewer M et al, 1997:4; World Bank, 1994 and 1996; U.N 1994:3) and confirmed by our findings are as follows:

1. Ownership and management are often held by one individual who exercise greater dominance and influence. Hence, ownership is highly family centered.

2. The small size and relatively short history of most SMEs often affect their behavior and performance

3. The inability to separate company's fund from proprietor's fund contributes to the inefficiency in financial management of many SMEs and their inability to easily secure loans from financial institutions

4. SMEs are more reluctant at taking risks on new ventures because for their low capital base and low level of qualified employees.

5. Reluctance in shifting production from an old product to an entirely new product.

6. Many SMEs are family businesses and as such performance standards are almost impossible to establish and enforce.

\section{Major problems or constraints of small and medium scale enterprises.}

Osanwonyi and Tafamel (2010, pp 195-196) is of the opinion that the major problems faced by small and medium scale enterprises are;

Poor and inadequate start up process: The start-up process of a business is important to its failure or success. Nzeribe (1996) opined that business especially small ones are started by the entrepreneurs and are usually guided by a vision, an intuitively experienced image of what it to be achieved and how to get there. The way an entrepreneur structures and creates his business reflects his personality, and cannot be transferred to his successor. The severity of the succession problems in family businesses is significant in their success and any future combination.

Financial problems: The problem with funding of SMES has to do with sourcing and accessibility. Factors inhibiting funds accessibility of SMEs are the stringent conditions set up by the financial institutions, the lack of adequate collateral and credit information and the cost of processing funds.

Management Problem: Technical problems/competence and lack of essential and required expertise in production, procurement and maintenance, marketing and finances have always led to fund misapplication, wrong and costly decision making. Lack of trained manpower and management skills constitute major challenges to survival of SMEs.....inefficiency in overall management and poor record keeping is a major feature of SMES.

Lack of Infrastructural Development: The problem of infrastructure ranges from shortage of water supply, inadequate transport system, lack of electricity to solid waste management. Governments have not done enough to create the best conducive environment for the striving SMEs thus businesses have to provide expensive parallel infrastructure.

Strategic Planning Problems: Sound planning is a necessary input to a sound decision-making. 


\section{SMEs often do not carry out proper strategic planning in their operations.}

A major challenge to the success of SMEs in Nigeria is irregular power supply which requires urgent genuine government attention if the vision 2020 project is to be achieved (Chiedu, 2012).

SMEs also face the problem of low patronage. Most Nigerians have developed a high propensity for the consumption of foreign goods as against their locally made substitutes thus making the market for locally made goods to be poor.

\section{Research Design and Methodology}

The study has been narrowed down to three lines of business in Edo State, these are welding, shoe making and tailoring. The random sampling method has been used in generating respondents for the questionnaires and interviews. The data was collected by combining primary sources with secondary sources. The main data instrument employed is the questionnaire. The questionnaire was design as multiple-choice and open ended. Interview of the owners and managers of SMEs were also used to supplement the output.

\section{Data Analysis}

A total of 105 copies of the questionnaires were distributed, 105 was retrieved and useful. The response rate is a satisfactory $91 \%$ and the distribution as in table 2 below.

From table 3 , it was seen that majority of the SMEs are one-man business with a response rate of $90.48 \%, 1.90 \%$. This indicates that most SMEs in Edo State are sole proprietorship. Majority of those who manage SMEs in Edo State pass through apprenticeship with $23.81 \%$ and are poorly educated WASC/SSCE 33\%. The meaning of this that SMES owners may not be informed enough to respond to enlarged and heightened competition of modern business. The table reveals that $50.48 \%$ of them indicated age of business of one to five years while $43.81 \%$ indicated age of between 5-10 years. This picture shows a weak educational background. From table four, 52.14\% respondents believe that their present level of education is not adequate for effective management of their business operations. Inspite of this, 59\% rejected the infection of additional qualified personnel into their business for fear of that they may take over the business $(38.10 \%)$ and reduction in profits resulting from additional employing a staff. Also, it is clear that most SMEs owners require loan to finance their operation of their business. This is evident from the $57 \%$ positive response. $60 \%$ of the respondents require loans from specialized government agencies and institutions while $40 \%$ prefer short term loans and overdrafts.

From table 5, 86 respondents $(81.9 \%)$ agree that they have problems obtaining funds from governmental banks and financial institutions. This may be due to inability to meet the strict conditions and terms of loans demanded by the banks. This may inhibit their desire scope of expansion and the level of productivity and in some cases result to closure. This is shown by $50 \%$ response. $19 \%$ respondents say they do not understand banks procedures and requirement while $28.57 \%$ attributed it to lack of collateral security. $76 \%$ of the respondents believed that the problem can be resolved while $23.8 \%$ of the respondent that the problem cannot be resolved. The table shows that $80 \%$ of the respondents believe that the government have a greater role to play in resolving fund accessibility while $20 \%$ disagree implying that the SMEs owners have a greater role to play.

Table: shows option strategies employed by thriving SMEs. The rating can be seen on the table.

\section{Recommendations and Conclusion}

\subsection{Summary of findings}


- SMEs have seriously impacted in the areas of employment, development of indigenous industrial sector

- Ownership/ management of these SMEs are mainly managed by individuals who do not have adequate qualification and management experience to effectively manage their business in a challenging environment.

- Problems facing the SMEs in Edo State include poor management, lack of access to financing, inadequate policy environment and lack of technological know-how.

- Governments in conjunction with the owners of SMEs have a great role to play.

- The options employed to survive by striving SMEs include creativity and innovation in product packaging, use of trained employees, political patronage and relationship, creative financing, planning, committed response to stakeholders, understanding of market and response flexibility and personal commitment.

\subsection{Recommendations}

- The SMEs owners should be committed to their business and be growth oriented rather than consumption oriented.

- Informal education of SMEs owners should be promoted through seminars and workshops which should be organized regularly to create forum for interaction of SMEs owners/managers with other and thereby improving on their management capabilities.

- The various loan guarantee schemes of government, its agencies as well as banks should learn the operational methods of NGOs that have been successful in finding SMEs.

Table 1: Distribution and Return of questionnaires

\begin{tabular}{|c|c|c|c|c|}
\hline SMEs & Questionnaires Distributed & Total Returned & Total returned & Total \% of total response \\
\hline Welding & 25 & 20 & 5 & 19.05 \\
\hline Shoe making & 37 & 35 & 2 & 33.33 \\
\hline Tailoring & 53 & 50 & 3 & 47.62 \\
\hline total & 115 & 105 & 10 & 100 \\
\hline
\end{tabular}

Source: Survey returns

Table 2: Analysis of ownership structure, qualification

\begin{tabular}{|l|c|c|}
\hline \multicolumn{1}{|c|}{ Ownership structure } & No of Respondent & Percentage \\
\hline One man business & 95 & 90.48 \\
\hline Co-operative society & - & - \\
\hline Partnership & 8 & 07.62 \\
\hline Limited liability & - & - \\
\hline others & 2 & 1.90 \\
\hline Total & 105 & 100 \\
\hline
\end{tabular}

\begin{tabular}{|l|c|c|}
\hline \multicolumn{1}{|c|}{ Owners Qualification } & No of Respondent & Percentage \\
\hline First school leaving certificate & 43 & 40.95 \\
\hline WASC/SSCE & 35 & 33.33 \\
\hline OND/NCE & 02 & 1.9 \\
\hline BSC/HND & - & \\
\hline MBA/MSC & - & \\
\hline Apprentice & 25 & 23.81 \\
\hline Total & 105 & 100 \\
\hline
\end{tabular}




\begin{tabular}{|l|c|c|}
\hline \multicolumn{1}{|c|}{ Age of Business } & No of Respondent & Percentage \\
\hline $1-5$ years & 53 & 50.48 \\
\hline Between 5-10 years & 46 & 43.81 \\
\hline 10 years and above & 0.6 & 5.71 \\
\hline Total & & 100 \\
\hline
\end{tabular}

Table 3: Survey responses to questions on qualification to funding

Do you think your present level of qualification and experience is adequate for your business in a difficult economic situation?

\begin{tabular}{|c|c|c|}
\hline Responses & No of Respondent & Percentage \\
\hline Yes & 45 & 42.86 \\
\hline No & 60 & 57.14 \\
\hline Total & 105 & 10000 \\
\hline
\end{tabular}

Do you require additional qualified personnel to join in your management?

\begin{tabular}{|c|c|c|}
\hline Responses & No of Respondent & Percentage \\
\hline Yes & 43 & 40.95 \\
\hline No & 62 & 59.05 \\
\hline Total & 105 & 10000 \\
\hline
\end{tabular}

Reasons for rejection of additional qualification personnel

\begin{tabular}{|l|c|c|}
\hline \multicolumn{1}{|c|}{ Responses } & No of Respondent & Percentage \\
\hline Fear of taking over the business & 40 & 38.10 \\
\hline Fear of misunderstanding in the future & 20 & 19.05 \\
\hline Diffusion of control & 10 & 9.52 \\
\hline Cost of paying additional management & 30 & 28.57 \\
\hline Staff will be high and lead to reduction in profit & & \\
\hline others & 5 & 4.76 \\
\hline total & 105 & 100 \\
\hline
\end{tabular}

Do you have adequate finance for you business operations?

\begin{tabular}{|c|c|c|}
\hline Responses & No of Respondent & Percentage \\
\hline Yes & 38 & 36.19 \\
\hline No & 67 & 63.81 \\
\hline Total & 105 & 100 \\
\hline
\end{tabular}

Do you require loan for your business operations?

\begin{tabular}{|c|c|c|}
\hline Responses & No of Respondent & Percentage \\
\hline Yes & 60 & 57.14 \\
\hline No & 45 & 42.86 \\
\hline Total & 105 & 100 \\
\hline
\end{tabular}

From which source do you require loan to finance the operation of your business?

\begin{tabular}{|l|c|c|}
\hline \multicolumn{1}{|c|}{ Responses } & No of Respondent & Percentage \\
\hline Short term Bank loans and overdraft & 42 & 40 \\
\hline Long term Bank loans & - & \\
\hline
\end{tabular}




\begin{tabular}{|l|c|c|}
\hline $\begin{array}{l}\text { Loans from specialized government agencies and } \\
\text { institutions e.g. Micro credit schemes }\end{array}$ & 63 & 60 \\
\hline Total & 105 & 100 \\
\hline
\end{tabular}

Sources: Survey report

Table 4: Survey Responses to questions relating to details of funding

Do you have any problem obtaining funds from governmental Banks?

\begin{tabular}{|c|c|c|}
\hline Responses & No of Respondent & Percentage \\
\hline Yes & 86 & 81.90 \\
\hline No & 19 & 18.10 \\
\hline Total & 105 & 100 \\
\hline
\end{tabular}

What are the problems of obtaining loans from Banks and Financial institutions?

What are the problems of obtaining loans from Banks and Financial institutions?

\begin{tabular}{|l|c|c|}
\hline \multicolumn{1}{|c|}{ Responses } & No of Respondent & Percentage \\
\hline The company cannot meet the Banks lending requirement & 53 & 50.48 \\
\hline Lack of understanding of the Banks' procedures and requirement & 20 & 19.05 \\
\hline Lack of good project proposals & 02 & 1.90 \\
\hline Lack of collateral security & 30 & 28.57 \\
\hline Total & 105 & 100 \\
\hline
\end{tabular}

How can the problems of access to loans be resolved?

Do you think that these problems identified can be resolved?

\begin{tabular}{|c|c|c|}
\hline Responses & No of Respondent & Percentage \\
\hline Yes & 80 & 76.19 \\
\hline No & 25 & 23.81 \\
\hline Total & 105 & \\
\hline
\end{tabular}

Does the government at all levels have a major role to play in resolving these problems?

\begin{tabular}{|c|c|c|}
\hline Responses & No of Respondent & Percentage \\
\hline Yes & 84 & 80 \\
\hline No & 21 & 20 \\
\hline Total & 105 & 100 \\
\hline
\end{tabular}

What should government do to resolve the problem of obtaining loans form banks?

\begin{tabular}{|l|c|c|}
\hline \multicolumn{1}{|c|}{ Option } & No of Respondent & Percentage \\
\hline Encouraging Banks to provide loans to SMEs by guaranteeing such loans & 40 & 38.10 \\
\hline Create an enabling environment for value SMEs & 20 & 19.05 \\
\hline Provide training and educating SMES owners & 10 & 9.52 \\
\hline $\begin{array}{l}\text { Providing the loanable funds and banks should guarantee its effective } \\
\text { and efficient usage }\end{array}$ & 30 & 28.57 \\
\hline Others & 05 & \\
\hline Total & 105 & 100 \\
\hline
\end{tabular}

Source: survey report 
Table 5: Indicate the strategies for SMEs

\begin{tabular}{|l|c|}
\hline \multicolumn{1}{|c|}{ Options } & Score \\
\hline Creativity and innovative in product packaging & 86 \\
\hline Use of trained employees & 40 \\
\hline Political patronage and relationship & 65 \\
\hline Creative financing (especially from NGOs) & 84 \\
\hline Quality product & 79 \\
\hline Good location & 60 \\
\hline Planning & 75 \\
\hline Committed response to stakeholders & 85 \\
\hline Understanding of market and response & 75 \\
\hline Personal commitment & 92 \\
\hline
\end{tabular}

Note: Respondents gave multiple strategies

\section{Source: Survey Report}

\section{References}

Aregbeyen J.B.O (1999). Constraints of small and medium scale enterprises in sourcing funds from the Nigerian Stock Market. NISER Monograph series no. 5, Ibadan.

Dende, G.A. and Joshua, A.O. (2012). Roles and problems of Small-scale Business Development Programmes in Nigeria. International journal of management and business studies. Retrieved from www.ijmbs.com

Onyenechere, E.C. (2010). Appraisal of Rural Development Programmes in Imo State of Nigeria. Journal of Social Sciences 22(3)

Osamironyi, I.O. and Tafamel, A.E. (2010). Options for sustaining small and medium scale enterprises in Nigeria.

Rural Development (2013). Retrieved from http://en.wikipedia.org/wiki/rural-development.

Seyed, M.M.S. (2011). Small-scale Industries as focus on rural development. International journal of current research. Retrieved from http://www.journalcra.com

Yusuf, N.B. (2010). Economics of Small-scale Industries: A look at programmes for the growth and Development of Small-scale Industries in Nigeria. ICB, University of Kelaniya, Sri Lances 
